\title{
Evolution of the health sector and tuberculosis control in Brazil
}

\author{
Antonio Ruffino-Netto ${ }^{1}$ and Ana Maria Azevedo Figueiredo de Souza ${ }^{2}$
}

ABSTRACT Objective. To summarize the epidemiological situation of tuberculosis (TB) in Brazil, especially as it relates to the evolution of the health sector in recent decades, the process of health sector reform, and current proposals of the Brazilian Ministry of Health.

Methods. A review was conducted of data from the Ministry of Health of Brazil on tuberculosis in the country over the last 20 years, as well as of the history of changes in the health sector.

Results. There have been major changes in the epidemiological situation of TB and also in the structure of the health system in Brazil.

Conclusions. The overall prospects are promising for Brazil's National Plan for Tuberculosis Control.

Key words Tuberculosis, Brazil, health systems and services, health sector reform.

Among the countries of the world with a high burden of tuberculosis (TB) in 1998, Brazil ranked 13th (1). Over the past two decades the TB notification rate in Brazil has declined (2), as shown in Figure 1. Brazil achieved cure rates approaching the World Health Organization (WHO) target of $85 \%$ in the first half of the 1980s, but in recent years the percentage of cases cured has been around $75 \%$ (Figure 2).

The level of success achieved in the control and treatment of TB in Brazil in recent decades has been related to the evolution of the health sector in

\footnotetext{
Brazil, Ministry of Health, National Tuberculosis Program, Brasília, DF, Brazil. Send correspondence to: Antonio Ruffino-Netto, Medical School of Ribeirão Preto, Av. Bandeirantes 3900, Ribeirão Preto, SP, Brazil CEP 14049-900. Telephone: 0055-16-6023070; fax 0055-16-6331386; e-mail: aruffino@fmrp.usp.br

2 Brasil, Ministério da Saúde, Agência Nacional de Vigilância Sanitária, Brasília, Distrito Federal, Brasil.
}

the country and to the nation's process of health sector reform. The remaining sections of this paper will attempt to profile that relationship.

\section{THE HEALTH SECTOR AND TUBERCULOSIS CONTROL}

\section{Evolution of the health system in Brazil}

From the start of the twentieth century until after the Second World War the Ministry of Health of Brazil had responsibility for the country's public health system (3). Over these decades, campaigns were organized to control communicable diseases, combat malnutrition, and address the needs of specific groups, such as children and pregnant women. Workers received medical care from a system under the Ministry of Social Security.
Beginning in the late 1960s, large numbers of people moved from the rural areas to the big cities. The majority of these persons did not participate in the formal job market and were therefore not covered by the Social Security medical care services. In response, in 1975 the Government of Brazil approved legislation to reorganize the health sector and to define the responsibilities of the different stakeholders in the sector (3). Under the new law the municipalities were made responsible for operating the health services that addressed the health needs of the local populations.

In 1976 the Ministry of Health established two large programs that were aimed at improving health conditions by increasing health services coverage for populations that had had inadequate access. One of the programs was the National Program on Food and Nutrition, and the other was the Pro- 
FIGURE 1. Tuberculosis notification rate (per 100000 inhabitants), according to TB clinical form, Brazil, 1978-1997

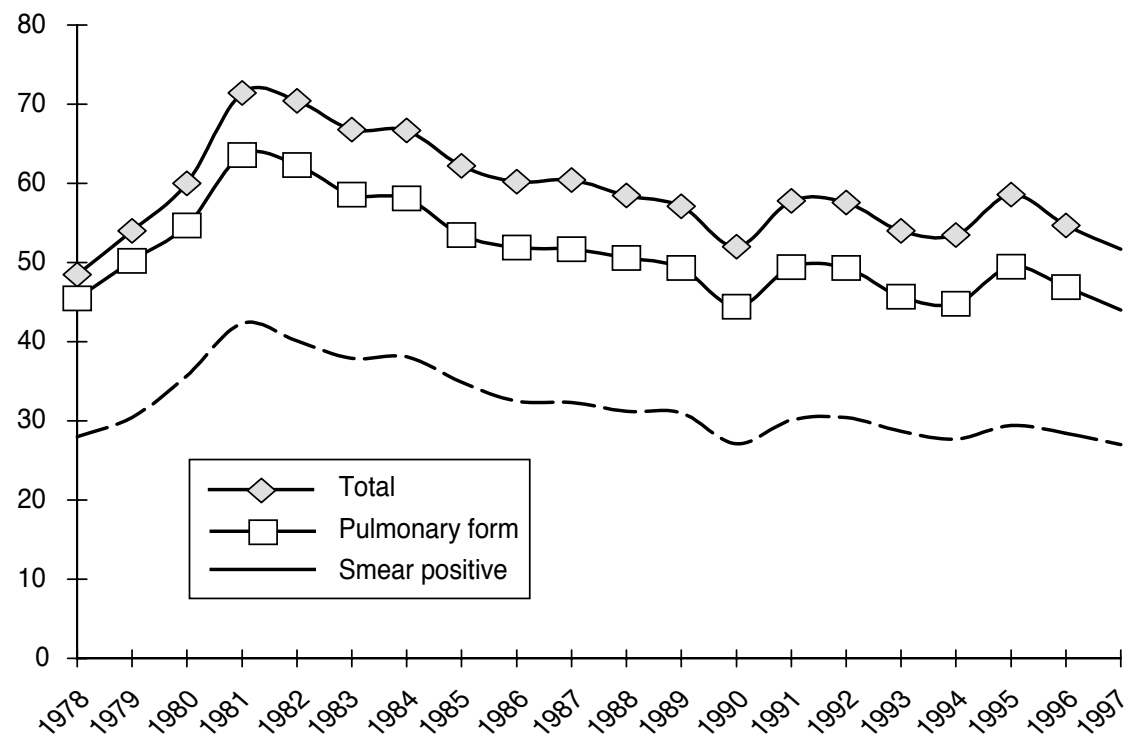

Source: Brazil, Ministry of Health. respiratory symptoms examined, and treatment default, and cure rate

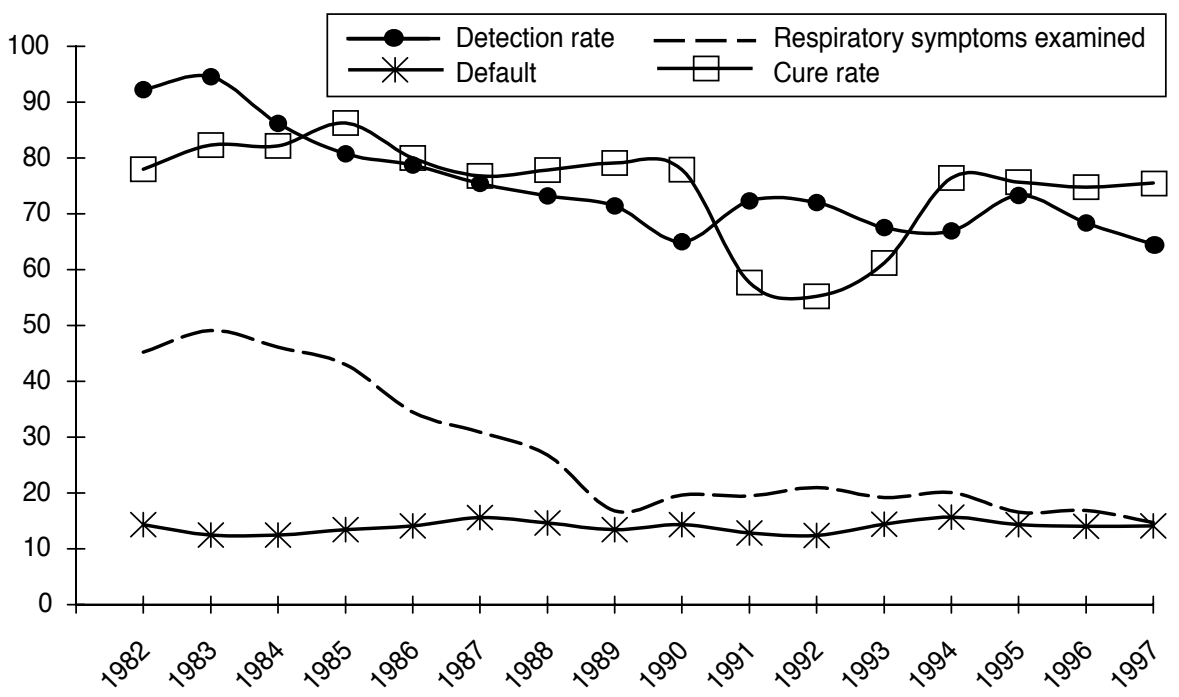

Source: Brazil, Ministry of Health.

gram of Actions in Health and Sanitation. The Ministry of Social Security supported these efforts by making resources available to populations that had not been covered (3). In 1977 the
Ministry of Social Security additionally established the National Institute of Medical Care and Social Security, to promote a more rational use of its health funds. In spite of these devel- opments, in the early 1980s a large proportion of the country's population still had no access to appropriate health care. This was particularly true for low-income persons who had no Social Security coverage.

In 1986 Brazil's Eighth National Conference on Health formulated principles on which to base a reform of the health system and address the problems of inequitable access to health services. The leading principles were the recognition of the right of all citizens to health and the reorganization of the health system into the Unified Health System, which would combine the health care services provided by the Ministry of Health and the Ministry of Social Security. In 1988 the country's National Constituent Assembly endorsed a new constitution that included the creation of the Unified Health System.

\section{Evolution of tuberculosis control}

The history of tuberculosis control in Brazil dates back to 1941, when the National Tuberculosis Service was created to study the magnitude of the TB situation and to develop disease control measures (4). The National Campaign Against Tuberculosis was launched in 1946. Between then and 1990 the National Tuberculosis Service was responsible for national coordination of $\mathrm{TB}$ control, with several reorganizations of the Service taking place over that period. In 1970 the Service became the National Tuberculosis Division, and in 1976 it was reconstituted as the National Division on Lung Health.

Although the WHO recommendation of directly observed treatment for TB is fairly recent, Brazil's public health service began using this approach in the early 1960s, with treatment done by nurses, and with coverage expanding over the years (5). In 1975 the Second National Development Plan of the Ministry of Health included tuberculosis control. Integrating the work of different government levels, the National Tuberculosis Program (NTP) was financed by the Ministry of Health, the National Institute 
of Medical Care and Social Security, and the state secretariats of health. A key objective was to coordinate and standardize TB control at the federal and state levels in accordance with national guidelines. This included providing TB diagnosis and free TB treatment on an ambulatory basis as an integral part of the health services, under the responsibility of non-TB specialists. In 1979 the NTP introduced short-course TB treatment, with 6 months of daily self-administered rifampicin, isoniazid, and ethambutol.

In 1981 the National Institute of Medical Care and Social Security, the Ministry of Health, and the state secretariats of health agreed to transfer the responsibility for TB control to the state level. As a result of the decentralization of the NTP, thousands of TB beds in public hospitals were no longer needed since the majority of TB patients were being treated on an ambulatory basis. Work absences due to receiving $\mathrm{TB}$ treatment declined substantially.

In 1990, for budgetary and efficiency reasons, the Government of Brazil decided to decentralize to the state level the national administrative functions, including the financial responsibility for TB control. As a result, the National Campaign against Tuberculosis ended and the NTP structure disappeared. Although the program at the national level was later re-instated as part of the epidemiological surveillance system, the capacity at the national level to coordinate TB control at the state level was weakened. Further, due to reduced financial resources, surveillance activities diminished and the quality of TB control at the state level deteriorated.

\section{Implementation of health sector reform}

The main objective of the health reform process in Brazil is to ensure universal access to integrated health services that provide preventive and curative care and that address both in- dividual and collective needs. The reform strategy chosen by the Ministry of Health involves decentralization of political and administrative responsibilities as well as community participation in health management issues. Federal, state, and municipal governments are each required to develop consolidated budgets for the financial, technical, material, and human resources needed to implement the new system in their respective areas.

Implementing health reform necessitated a reorganization of structures within the federal government. This was particularly true for the managing structure of the Ministry of Health, which had to be adjusted in view of its new responsibility of coordinating the reformed health system. The National Institute of Medical Care and Social Security was abolished in 1993 and the Ministry of Health took over its functions. The Ministry of Health established policies to guide decentralization and the transfer to the municipalities of the management of health services. Referred to as "health municipalization," this process included the provision of financial resources to the municipalities through a management policy agreed to by the federal, state, and municipal governments. A national information system, still being developed, monitors the results of this process, with the goal of improving the distribution of resources to the various regions of the country.

Since 1994 the municipalities have progressively taken responsibility for managing and providing health services, while the federal and state governments have provided funds to the municipality level. Currently nearly all of the 5600 municipalities in Brazil are responsible for the implementation of a basic health care package. The participation of civil society in the management of the Unified Health System is an important component of the health reform. By law, as an essential condition for implementation of reform, health councils are organized at the national, state, and municipal levels to discuss health problems.

\section{TB control as part of health sector reform}

In accordance with the health reform policy, in 1992 the responsibility for monitoring and evaluating TB control, TB public campaigns, and training of TB staff was transferred from the federal to the state level. In line with the same policy, the municipalities were made responsible for diagnosing and treating TB.

Because of the growing co-epidemic of TB and HIV / AIDS in Brazil, in 1994 an Emergency Plan for Tuberculosis Control was developed by the Ministry of Health. The Emergency Plan included financial support from the Ministry of Health based on approximately US\$ 100 per estimated case of tuberculosis. Finances would be provided following agreements between the municipalities and the National Foundation of Health, which is part of the Ministry of Health. However, according to consultants from $\mathrm{WHO}$ and the Pan American Health Organization, the Emergency Plan was not adequately implemented and therefore had little impact.

Recognizing the size of the TB problem in Brazil, in 1998 tuberculosis was declared a priority health problem by the National Council of Health, which includes representation from the national, state, and municipal governments and also from nongovernmental organizations. The National Council said that the Emergency Plan needed adjustments, but that the situation could and should be corrected with the available resources. Subsequently, a National Plan for Tuberculosis Control was developed. Among the objectives of the National Plan were, by 2001 , to detect $92 \%$ of estimated cases and to cure at least $85 \%$ of these cases (6). Other objectives were, by 2007, to reduce incidence by $50 \%$ and mortality by two-thirds.

Under the National Plan, the Ministry of Health is responsible for establishing standards for TB control, procuring and providing drugs, developing laboratory and treatment 
guidelines, coordinating the surveillance system, furnishing technical support to states and municipalities, and providing intersectoral coordination. The National Plan stipulates the need to coordinate federal, state, and municipal efforts as well as the need for community participation and the involvement of nongovernmental organizations. The recommended practice for detecting and diagnosing TB cases is smear examination of sputum from persons with respiratory symptoms and those persons' contacts. The recommended treatment is directly observed intake of anti-TB drugs, to be supported by a regular supply of TB drugs and strategic reserve stocks. Municipalities receive US\$ 100 per case cured when directly observed treatment is utilized and US\$ 67 per case cured when patients undergo unsupervised treatment. The new plan also recommends establishing a drug resistance surveillance system.

\section{DISCUSSION}

Following the adoption of Brazil's new constitution in 1988, the administrative and financial responsibility for the control of tuberculosis was effectively decentralized to the state and municipality level as part of health reform. This new health system structure offers both opportunities and challenges for TB control in Brazil.
The decentralization of health services to the municipalities and the creation of health councils provide a possibility for the public to demand health services that are conducive to the implementation of supervised treatment. Integrating TB control activities into the general health services promotes better access to TB diagnosis and treatment. Also important are the active involvement of the private sector and the participation of the community in case detection and support for patients.

There are also ongoing challenges for the reformed, integrated health system. The system needs to maintain the quality of TB diagnosis and treatment activities through clear definitions of responsibilities and by providing adequate technical support. Another key issue is the availability and quality of TB drugs in the decentralized system. Given that Brazil has 5600 municipalities, a well-defined national system is needed to monitor and evaluate the quality of TB control at the municipal level and to allow for timely support where results fall below set standards.

There are risks connected to the health reform process. In the decentralized system, municipalities may give insufficient priority to TB control and may not follow the required national guidelines. In addition, the laboratory network and the human resources needed to implement supervised $\mathrm{TB}$ treatment are not yet adequate in all of Brazil's municipalities.

In general, the prospects for the National Plan for Tuberculosis Control are good. The Government of Brazil has a clear understanding of the association between TB and socioeconomic development. It is aware of the large social inequalities in the country and that the less-privileged populations are vulnerable to TB and other diseases.

The political decision by the National Council of Health in 1998 to declare TB a priority disease has increased state and municipal commitment to controlling the disease. The decentralized structure of Brazil's health system further offers a good opportunity to implement the National Plan for Tuberculosis Control. Similarly, the newly introduced bonus system for cured cases is an incentive for municipalities to implement supervised treatment.

In implementing the National Plan for Tuberculosis Control as part of the health reform process, the Ministry of Health needs to maintain an equilibrium between TB efforts at the municipal level and those at the state and federal levels. That is, general TB activities at the municipal level must be balanced with the specialized TB functions at the state and federal levels such as national TB surveillance, TB drug procurement and supply, technical support and supervision, and monitoring and evaluation of municipallevel TB efforts.

\section{REFERENCES}

1. World Health Organization. Global tuberculosis control. WHO report 1998. Geneva: WHO; 1998. (Publication WHO/TB/98-237).

2. World Health Organization. Global tuberculosis control. WHO report 2000. Geneva: WHO; 2000. (Publication WHO/CDS/TB/2000.275).

3. Braga JCS. Saúde e previdência. Rio de Janeiro: HUCITEC; 1985.
4. Ruffino-Netto A. Impacto da reforma do setor saúde sobre os serviços de tuberculose no Brasil. Boletim de Pneumologia Sanitária 1999; 7(10):7-18.

5. Rocha ATS. Padrões de controle da tuberculose na comunidade. In: Situação e perspectivas do controle das doenças infecciosas e parasitárias. Brasília: Universidade de Brasília; 1981. p. 127-132.
6. Brasil, Ministério da Saúde. Plano Nacional de Controle da Tuberculose. Brasília: Ministério da Saúde; 1999.

Manuscript received 23 October 2000 and accepted for publication on 11 April 2001. 
RESUMEN Objetivo. Resumir la situación epidemiológica de la tuberculosis en Brasil y, en particular, su relación con la evolución del sector de la salud en las últimas décadas, con el proceso de reforma del sector de la salud y con las actuales propuestas del Ministerio de Salud de Brasil.

\title{
Evolución del sector de la salud y control de la tuberculosis en Brasil
}

Métodos. Se efectuó una revisión de los datos del Ministerio de Salud de Brasil acerca de la situación de la tuberculosis en el país durante los últimos 20 años, así como de la historia de los cambios sufridos por el sector de la salud.

Resultados. En Brasil ha habido importantes cambios en la situación epidemiológica de la tuberculosis y en la estructura del sistema de salud.

Conclusión. El Plan Nacional de Control de la Tuberculosis en Brasil tiene, en general, prometedoras perspectivas.

\section{American Public Health Association 129th Annual Meeting \& Exposition}

\author{
Dates: $\quad$ 21-25 October 2001 \\ Location: Georgia World Congress Center \\ Atlanta, Georgia, United States of America
}

This year's annual meeting of the American Public Health Association (APHA) has the theme of "One World, Global Health." The APHA is the oldest and largest organization of public health professionals in the world. APHA members include researchers, health service providers, administrators, teachers, and other health workers.

More than 12000 persons are expected to attend the APHA meeting. The meeting will feature over 900 scientific sessions, awards programs, poster sessions, workshops, and business meetings. Speakers at the opening general session will include Dr. Gro Harlem Brundtland, Director-General of the World Health Organization, and Rosalynn Carter, wife of former United States President Jimmy Carter. The closing general session will feature Dr. Louis Sullivan, the President of the Morehouse School of Medicine and the former Secretary of the United States Department of Health and Human Services. The meeting's public health exposition will have more than 550 booths.

The meeting registration fee is US\$ 265 for members and US\$ 405 for nonmembers, if paid in full by the "early bird" deadline of 17 August 2001.

Information:

American Public Health Association

800 I Street, NW

Washington, D.C. 20001, United States of America

Telephone: (202) 777-2742

Fax: (202) 777-2532

World Wide Web site: http://www.apha.org 